\title{
The Research on Safety Children's Travel Route on Child-Friendly City of Netherlands
}

\author{
Cai Liangwa \\ School of Architecture, Tianjin University, Tianjin, China
}

Email address:

cailw@163.com,tju_zeng@163.com

To cite this article:

Cai Liangwa. The Research on Safety Children's Travel Route on Child-Friendly City of Netherlands. International Journal of Environmental Protection and Policy. Vol. 5, No. 6, 2017, pp. 94-98. doi: 10.11648/j.ijepp.20170506.12

Received: November 8, 2017; Accepted: November 22, 2017; Published: December 29, 2017

\begin{abstract}
The child-friendly urban space does not mean to build a child-dominated block or city, but means to enhance the child-friendly degree of the original block or city through planning, management and other measures. In the case, based on the original city, "child-friendly" blocks shall be established to provide children with a safe social environment, an improved road system for walking and cycling and an attractive environment that can trigger games. In the last century, the concern for the environment of the block and children's rights and needs prompted many countries to conduct a series of block environmental improvement practices. For example, the concepts of Woonerf and Kindlint in Netherlands were both established to ensure that the child can freely, safely and independently get around. They all try to make the needs of children as measurement to achieve the purpose that residential blocks can satisfy the interests of all people and friendly to all users. Based on the concept of "child-friendly city", after the analysis on related cases about the transformation of child-friendly blocks in Amsterdam, Delft and other cities, the paper makes a summary of concepts and implementation methods about planning and design of safe blocks and Kindlint. With a comparison of inadequate related planning in Chinese urban residential areas, it expects to provide useful experience for improving child friendliness of Chinese residential areas and cities.
\end{abstract}

Keywords: Safety in Residential Area, Child-Friendly City, Children's Travel Route (Kindlint), Planning and Design

\section{Child-Friendly City and Child-Friendly Blocks}

Aimed at the living conditions of children in the city, in 2004, UNICEF released an action framework for child-friendly cities and proposed to protect 12 rights of children in urban construction, such as walking alone safely in the streets, meeting to play with friends, living in green environment away from pollution and so on. Child-friendly urban construction does not need to be child-oriented and it just requires proper re-design of urban roads, public spaces and event facilities in the city and community building and renovation design and take care of the interests and special needs of children in urban construction. Child-friendly city is an index to measure city-building; if the city or residential area is child-friendly, then it is usually friendly for people with disabilities, the elderly and other persons with special needs, and it is able to take care of needs of everyone in the city. [1]
In August 2005, Childstreet 2005 International Seminar was held in Delft, Holland, attended by 80 people from 22 countries including landscape planners, architects, sociology scholars, politicians and parents from all walks of life. In the latter Delft Declaration issued in 2006 - "Exploration for Child-friendly Streets" (Een KiSS voor Childstreet - Een verkenning van de kindvriendelijke straat), the design concept of "child-friendly" district environment was proposed which attempts to find a balance between the motor vehicle and outdoor activities for children on the basis of not increasing the number of existing motor vehicles to encourage adults and children to walk or go by biking. [2] It aims to provide security for walking, cycling and getting around independently of children and prompt more scenes in the life to take place in the outdoor space. During the seminar, the participants divided into several groups made investigation of the residential area in Poptahof, Delft. They discussed with the surrounding residents and children to assess the "child friendliness" of the block and then made suggestions on improving the block. [3] 
The seminar proposed the concept of "child friendliness" KiSS (Kinder Straat Scan) of blocks and roads to make an objective assessment of the suitable extent of roads for walking and cycling. Assessment on "child friendliness" KiSS has six principles: 1. Provide adequate protection including the social environment and road environment; 2 . It is walkable and has safe pedestrian system; 3. It is suitable for children bicycling and has a safe and independent bicycling system; 4 . It provide freedom for children to act on the street; that is, children can use the road in the full width; 5 . It has perfect and abundant street furniture; 6 . It has street environment attractive to children and can provide opportunities for children's games and social activities. [4] In accordance with these principles, since the 1990s, Holland has begun to launch the child-friendliness improvement work in all aspects of urban roads, public space and event facilities in the country and the main planning measures are the following. [4]

\section{Limit - Lower Speed of the Vehicle in the Block and Increase the Children's Wishes to Go out}

As early as 1979, the Swedish scholar proposed collision result of motor vehicle was directly related to its speed and established the curve between the vehicle speed and mortality of pedestrians in frontal collision. The figure shows when the vehicle speed is above $30 \mathrm{~km} / \mathrm{h}$, the mortality curve rises steeply. On the basis, Delft Municipal Government and the Dutch Cyclists Union implemented a project called the "Right of Way for Kids" in the 1990s to improve traffic safety environment around the school and encourage children to go school by walking and cycling. The most important measure is to strictly limit the speed of motor vehicle in the block around the school to be 30 kilometers per hour. [5]

Poptahof community located south of the city of Delft in Holland was built in the 1960s. It is a vibrant block with multi-ethnic settlements. The residential area includes six high-rise residential and commercial buildings, primary school and other buildings. The block is surrounded by tram tracks, four main urban expressways. As the residential areas presented a series of problems such as old construction, damaged infrastructure, lack of public services, open space in chaos, random parking, crime, rising unemployment and other issues, in 2004, Delft Municipal Government began to make substantial modifications for buildings, roads, landscape and open spaces in the residential area. The project began implementation in 2006 and was expected to be totally completed in 2021. [6] As the most active promoter of the idea of "Child Friendly City", at the beginning of the transformation of the Poptahof community, Delft Municipal Government established the road and landscape reformation principle to ensure priority of children's outdoor activities and cycling.

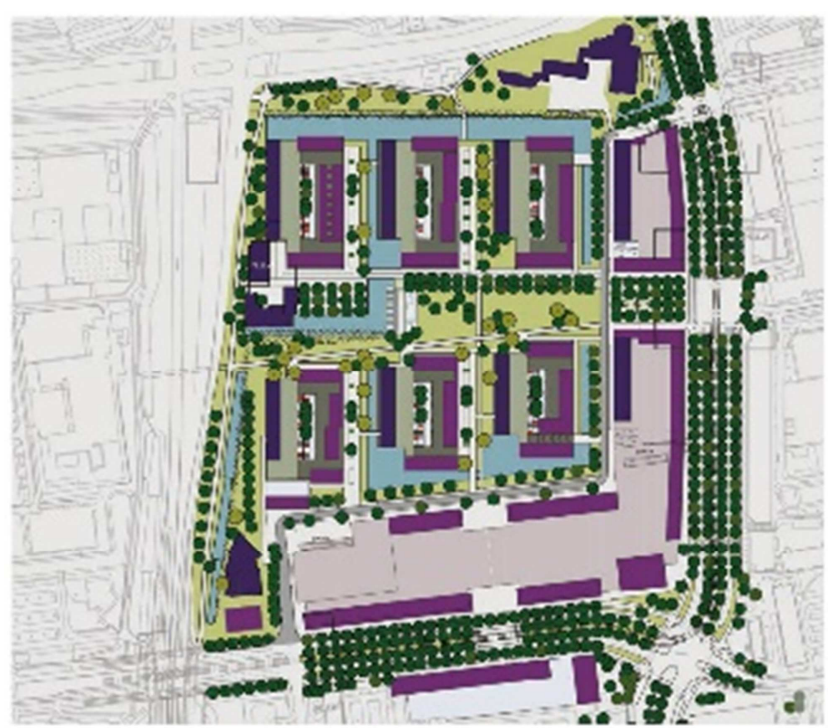

Figure 1. The Total Plane after Transformation.

First, it adjusts the level of regional roads and reduces vehicle speed in the region below 20 kilometers per hour in order to reduce security threats of the vehicle to children. Before the transformation, there were five north-south roads and four east-west roads in the community all of which were for vehicles. There were a total of six entrances and had direct access to the city roads. After the transformation, there is only an L-shaped road in the southeast set with pedestrian trails and independent bike paths that allows vehicles to drive through the community. In some places of the road where motorized vehicles need to go across, deceleration zones, zebra crossings and marks are set to felicitate children and people unable to move freely to go through it and reach the center green land. Secondly, it reduces vehicles' passing rate and encouraged cycling. After the transformation, the community has a complete cycling system and is directly connected to urban road network for slow moving. Slow path on the south side of the center green land connects independent bicycle path on the north-south main road of the east side of the block and elementary school on the west of the community. Then through the sinking tunnel, it passes through the fast path on the west side and reaches the opposite block, so residents including children in senior grade of the primary school can access safe and convenient cycling cells. Finally, comfortable walking paths in the block all pass by residential buildings, green land, waterside and places for children's activities. These walking paths have a width of 2 to $3.5 \mathrm{~m}$ and have significant differences from vehicle paths in the form of pavement and the material. At the intersection, the walking path uses the ramp to reduce difference in height; deceleration zone is set in the area around $2 \mathrm{~m}$ of the zebra crossing to alert motor vehicles and bicycles passing by to slow down. As a result, most of the residents' living space will not be affected by vehicles, thereby increasing children's willingness to travel alone; it also ensures safety of children playing independently in the block. (Figure 1) 


\section{Linkage - Plan the Children's Travel Route and Connect Daily Activity Places of Children}

In the child-friendly city theory, there are a lot of studies on independent mobility of children in the city. These studies and practice seek to link children and the block they make activities more closely. To enable children to safely and independently move in the block, the road space for children's travel needs to be reasonably planned to link children's everyday places such as home, school, green spaces and playgrounds through reasonable and safe paths." children's travel route" literally translated as "kid grid" (Kindlint) is the most important measure in the "Children Safer in Delft" implemented in Delft, Holland. [7] It is committed to constructing safe and funny corridors for children to provide children with: Sufficient space required to play and move; safe intersection; increased chances of independent travel; connecting various places frequented reached by children; children are not the only beneficiaries, but the elderly, the disabled and other vulnerable groups can also benefit from convenient and comfortable walking and cycling system. (Figure 2)

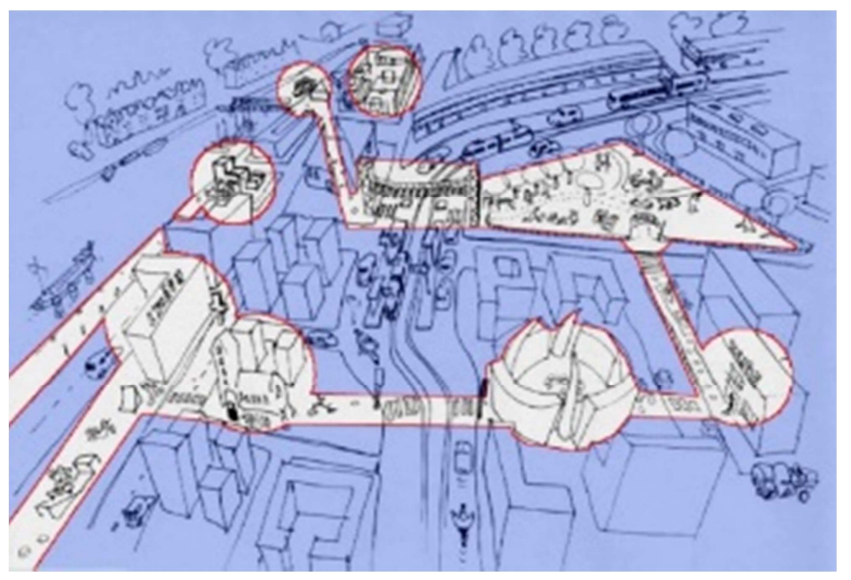

Figure 2. Linkage and Integration of the Daily Activity Places of Children.

The first "children's travel path" established in Delft is in Voordijkshoorn block. It links two primary schools, a kindergarten and five venues in the block through the security corridor. Along the security corridor, children can reach all destinations in the block by walking or biking. The first and most important step of the project is that it needs participation of children, because the travel habits of children and adults are different. Compared to going along the straight road, they tend to choose a more attractive place or shortcuts and alleys. Even travel habits of boys and girls are not the same; in the route from A to B, boys tend to go along the curved path by staying at several points and then going to the place, while girls usually choose a shortcut from A to B directly. Therefore, it is very important to respect for the child's travel habits and make targeted road reconstruction, rather than just make a simple transformation of urban roads. In the case of Delft, it first asks the views of children and let children mark their respective frequented visited destinations, favorite walking paths and dangerous locations they think with eight different colored lines on the block plan. Thereafter, by referring to interviews with residents and involvement of municipal personnel, the planners draw collected results into the habitual walking routes and then proceed to build recognizable children's travel route. (Figure 3)
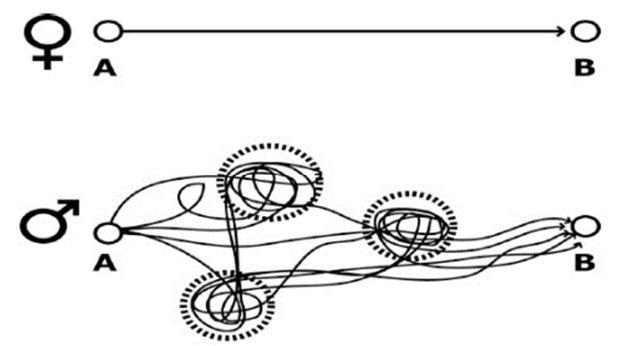

Figure 3. Travel Route of Boys and Girls on the Street.

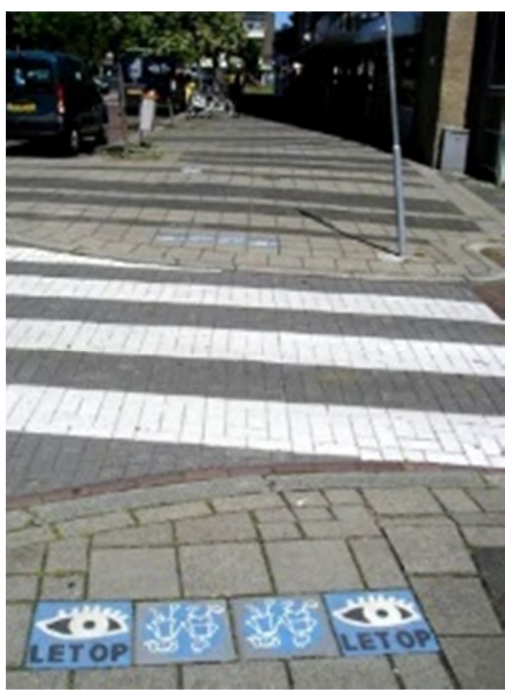

Figure 4. Marks on Intersections.

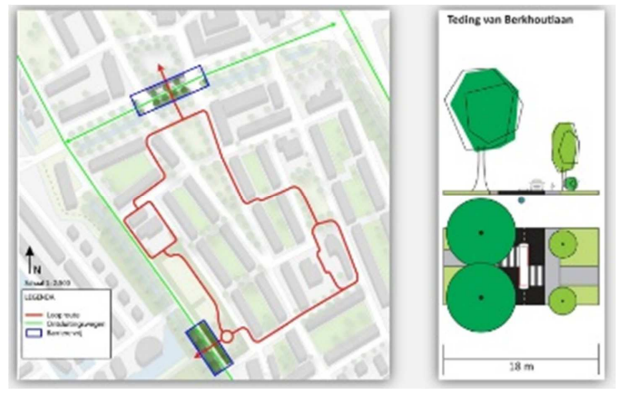

Figure 5. Design of Passing across Intersections of Vehicle.

Specifically, on a preset route, a tile with a special pattern is laid every three meters to clearly identify the walking route. On the route, four blue tiles are set side by side in the road intersections of the block to remind children to stop to look around; a deceleration zone two meters wide with warning signs and marks is set around zebra crossing to alert the driver to look over children passing across; the width of individual pavement is narrowed from six meters to four meters to reduce the distance to go across the road. On the urban road across the 
north of the street north of the block, there are separate bike lanes and separate pedestrian trails and the eye-catching logo (not implemented) is designed to remind passing drivers. To ensure safety, on the path and around the site for activities, a series of "Street Eyes" are set up to ensure buildings facing the main streets and playgrounds to have a good line of sight to facilitate people in the block to make a timely detection of threat from strangers and motor vehicles. (Figure 4; Figure 5)

\section{Sharing - Improve the Use Efficiency of Roads in Residential Area and Allow Children to Use the Full Width of the Road}

One of the most important criteria in child-friendly assessment is whether it can provide children with the freedom of action on the streets and whether children can use the full width of the road. Many parents and urban planning managers believe that well-designed game fields, reasonably planned parkland and rich and sate equipment for activities are essential evaluation criteria for a child-friendly city, but in fact a large part of children's game activities occur on the street in front of their own house and its subsidiary space. Safe block under the concept of child-friendly city should accommodate all daily activities of residents and establish a shared space for pedestrians, children's games, motor vehicles and bicycles through design. In the case that vehicle speed and driving path has been effectively controlled, the common functioning of plane form of roads, traffic signs, pavement, vegetation and outdoor furniture can ensure vehicles and children live in peace.

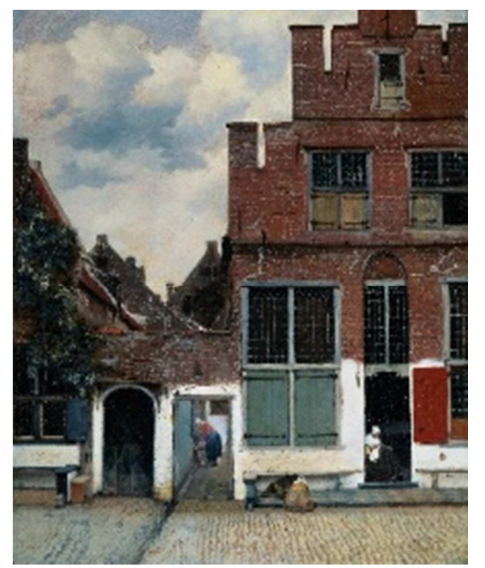

Figure 6. Vermeer's Famous Painting The Little Street.

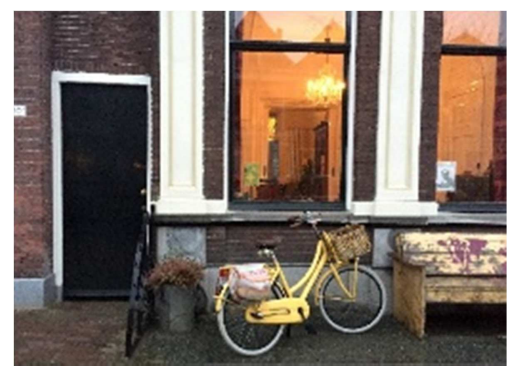

Figure 7. Vlamingstraat Street is Still a Semi-private Space.
The waterfront street unique in Dutch has been a shared living space in the history. Enkhuizen Street in 1886 described by Cornelis Springer was also a shared street space accommodating children's playing, pedestrians, horse-drawn carriage and commercial functions. The Little Street, one of Vermeer's famous paintings, depicts semi-private space of little street Vlamingstraat in Delft in front of the residence. A woman is patching clothes, while looking after children playing in the street. Today the road is still a shared road by motor vehicle and bicycle and retains private space. In the last century from 1960 s to 1970 s, with the popularity of cars, it had become impossible to completely prohibit motor vehicles to enter and pass the inside residential areas; besides, the residents themselves also want to park in front of or nearby their own houses. [8] Thus, the Dutch scholar Nick de Boer and his students Joost Vahl proposed the concept of Woonerf, advocating implementation of pedestrians and vehicles mixed road mode with limited vehicle speed and flow of people without a threat to living functional scope of pedestrians and residents. On the road, pedestrians and residents along the street have priority; driveways and sidewalks are not particularly distinguished and the two basically have no elevation difference, or the same kind of paving material is directly used. The vehicle speed is limited to about $20 \mathrm{~km} / \mathrm{h}$ and the length of the street is no more than $500 \mathrm{~m}$; it takes 1.5 to 2.5 minutes for the car to go from one end to the other end at the slow speed. (Figure 6; Figure 7; Figure 8)
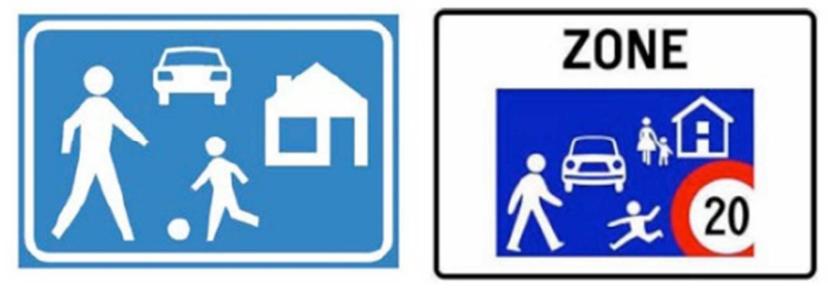

Figure 8. Signs of Shared Street.

To make children and other residents walk through the road in a residential area, parking on the road of the residential area should avoid continuous long-distance arrangement as much as possible; a secure channel to go across the street is set up about each 30 meters. After two or three parking spaces are recessed along the road, sidewalks are widened; after a distance, rearrange recessed parking spaces; Another approach is arranging staggered parking spaces to form a wide street sidewalk that can place simple game equipment or benches, so that child can conduct activities in front of their own home. Meanwhile, combined with deceleration strip, logo, green land and passing tunnel, both sides of the road are connected, so that the kids can safely cross the street to play with partners. [9] In public green land of residential areas and around children's playground, as the overall block traffic environment is safer, parking space is usually compatible with other activities. Especially during the day, when parking space for vehicle is free, children will play in the vicinity, so parking space is not empty. (Figure 9) 


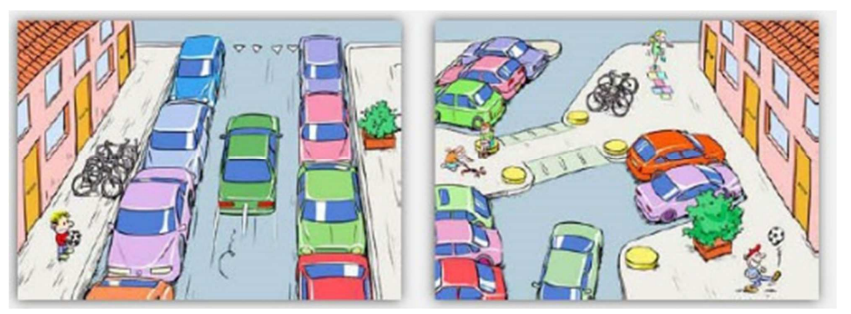

Figure 9. Ideas of Parking in Shared Street.

\section{Conclusion}

As for related research and practice in the field of safe residential areas and child friendly blocks, a number of cities in China such as Beijing, Nanjing, Hangzhou, Chengdu, Shijiazhuang, Jinan, Zhengzhou and Tianjin have proposed goal of building "child-friendly cities". [10] However, most cities are still at the public policy level and there are rare cases really implementing it in children's daily life aspects such as urban design, road safety assessment in residential area and landscape facilities.

As for the current situation of child friendliness in Chinese residential areas, on one hand, it is proposed to improve all levels of public green space and children's playing space to ensure that children's needs to make outdoor activities, get close to nature and make communication and enhance the safety, recreation quality, versatility, participation level and fun of space for children's activities. More importantly, through coordination in all aspects of careful research, public participation, policy support, plans implementation and monitoring mechanisms, it is recommended to make "child-friendly" system design for residential streets as previously described to form safe walking paths connecting daily activity places of children. It is recommended to establish a complete point and line combined spatial sequence for children's activities including clear space in front of the house, streets, public green spaces, playgrounds, schools and community centers to gradually develop a child-friendly urban space network. Safe travel routes and activities places built with the most vulnerable children's needs as the standard shall ultimately be the urban space meeting travel safety and social needs of the elderly, the disabled and other vulnerable groups.

\section{Acknowledgements}

Project supported by National Natural Science Foundation of China, Project Approval Number: 51408403.

\section{References}

[1] UNICEF. National Plan of Action for Children 2004[R]. Hague: Health, Welfare and Sport, 2004.

[2] Kind \& Samenleving - Ruimtecel, Kind \& Ruimte. Kindgerichte planning van publieke ruimte, Brugge, 2007.

[3] Gemeentedelft. Noordwest deelgebied, Hof van Delft/Voordijkshoom [R]. Delft: Gemeente Delft, 2008.

[4] Tjeerd Deelstra \& Eddie Kips. (2009). Een KiSS voor Child street - Een verkenning van de kindvriendelijke straat. Delft: the International Institute for the Urban Environment.

[5] Clarine J. V O. Independent mobility of schoo-aged children in Delft [R]. The Netheriands: Delft University of Technology, 2010 .

[6] Ashton, S. J. \& Mackay, G. M. (1979). Proceedings of the Conference of the International Research Committee on Biokinetics of Impacts (IRCOBI) on the Biomechanics of Trauma, 5-7 September 1979, Göteborg.

[7] Harm Tilman. (2006). "Brandingals instrument voor stedelijke vernieuwing". Delft: de Architect.

[8] SPRADON, S. Kindvriendelijke looproutes [D]. The Netherland: Delft University of Technology. 2011.

[9] Marketta Kytta. The extent of children's independent mobility and the number of actualized affordances as criteria for child-friendly environments [J]. Environmental Psychology, 2004, 24(2): 179-198.

[10] Carolyn Whitzman. Policies and practices that promote children's independent mobility $[\mathrm{J}]$. Urban Planning International, 2008, 23(5): 56-61. 